\title{
Desenvolvimento de Políticas Públicas em Educação a Distância no Semiárido: $O$ caso da implantação do EMITEC no Sertão Baiano
}

\author{
Eloi da Silva Pereira ${ }^{1}$; Sirius Oliveira Souza $a^{2}$
}

\begin{abstract}
Resumo: O presente trabalho trata-se de uma pesquisa exploratório qualitativa, com o objetivo de investigar quais os impactos da implantação do Programa Ensino Médio com Intermediação Tecnológica (EMITEC) em uma comunidade rural do semiárido baiano. Diante do contexto de educação à distância na educação básica e políticas públicas em educação este trabalho teve como sujeitos da pesquisa professores mediadores que atuam no programa supracitado. Os resultados permitiram observar a importância do EMITEC para a comunidade rural de Pindobaçu/BA e desafios a serem superados como a qualidade da conectividade via Internet dos alunos com o curso bem como o fomento à capacitação e formação dos profissionais do programa. Como destaque foi verificado que os mediadores cumprem adequadamente suas funções tanto nas questões técnico-administrativas quanto didáticas. Ressalta-se que os jovens da comunidade passaram a ter maiores perspectivas de crescimento profissional e buscar ampliar sua formação.
\end{abstract}

Palavras chave: EMITEC; Educação a Distância; Políticas Públicas.

\section{Development of Public Policies in E-learning in the Semi-arid: The case of EMITEC implementation in the Sertão Baiano}

\begin{abstract}
The present work is about a qualitative exploratory research, with the objective of investigating the impacts of the implementation of the Higher Education Program with Technological Intermediation (EMITEC) in a rural community in the semi-arid region of Bahia. Faced with the context of distance education in basic education and public policies in education, this work had mediator teachers who work in the aforementioned program. The results allowed observing the importance of EMITEC for the rural community of Pindobaçu/BA and challenging to be overcome such as the quality of Internet connectivity of students with the course as well as the promotion of training and training of program professionals. As a highlight it was verified that the mediators adequately fulfill their functions both in the technical-administrative and didactic aspects. It is noteworthy that the young people of the community started to have greater perspectives of professional growth and to seek to broaden their training.
\end{abstract}

Keywords: EMITEC; Distance Education; Public policy.

\footnotetext{
${ }^{1}$ Especialização Em Gestão Pública Municipal. Universidade Federal Do Vale Do São Francisco. 92eloi@ gmail.com;

${ }^{2}$ Licenciado em Geografia pela Faculdade Pitágoras - Unidade Teixeira de Freitas (PROUNI). Especialista em ensino de Geografia pela Universidade Estadual de Santa Cruz - UESC (2010). Mestre em Geografia pela Universidade Federal do Espírito Santo - UFES (2013). Doutor em Geografia pela Universidade Estadual de Campinas - UNICAMP (2017). Pós-Doutor em Geografia pela Universidade Estadual Paulista - UNESP - Rio Claro Professor Adjunto A da Universidade Federal do Vale do São Francisco, Brasil.
} 


\section{Introdução}

O presente trabalho pretendeu realizar uma articulação interdisciplinar entre a administração, educação e ciências sociais para abordar as contribuições da Educação a Distância (EAD) na educação básica, na rede pública de ensino do Estado da Bahia, destacandose o Programa Ensino Médio com Intermediação Tecnológica (EMITEC) desenvolvido na forma de política pública em educação.

O objetivo desse trabalho foi identificar quais os impactos da implantação da educação à distância no ensino médio, em especial em uma comunidade rural, do semiárido baiano? Para isso, levando em consideração o ponto de vista de professores mediadores de uma comunidade com polo do EMITEC na região de Senhor do Bonfim/BA; identificando suas potencialidades enquanto política pública em educação e analisando dados obtidos junto aos funcionários do programa.

Este trabalho surge da necessidade de se discutir a questão do acesso à educação de qualidade no semiárido baiano, enquanto política pública de Estado, e a importância do EMITEC para as pessoas dessas localidades da zona rural, em especial na cidade de Pindobaçu/BA, que não conseguiram ingressar e permanecer no ensino médio presencial em razão da inexistência de curso próximo às suas moradias.

A Bahia é o maior estado do nordeste brasileiro tanto em população quanto extensão territorial (IBGE, 2010). Nesse contexto, fatores adversos como difícil acesso, distância entre povoados e cidades e a falta de profissionais qualificados contribui para necessidade de interiorização e implantação da EAD na Bahia (SALDANHA, 2013).

Segundo Cassol (2001), os alunos do EMITEC através de tele aulas conseguem manter um vínculo com o presencial e transitar para a EAD e ter acesso a vários recursos tecnológicos, com destaque para as tecnologias da comunicação e informação (TIC) uma vez que a prática pedagógica do professor é mediada e digitalizada.

Pressupõem-se, portanto que a educação a distância, na educação básica em zonas rurais, poderá tornar-se uma importante modalidade de ensino para garantir aos jovens e adultos dessas localidades o direito à educação pública e gratuita. 


\title{
O Ensino Médio à Distância no Brasil
}

A educação à distância $(\mathrm{EAD})$ é uma modalidade de ensino reconhecida através da lei federal n. ${ }^{\circ}$ 9394/1996, Lei de Diretrizes e Bases da Educação Nacional (LDB), sendo garantida a sua oferta e assegurada gratuidade em espaços públicos segundo a Constituição Federal do Brasil (CF) de 1988. De acordo com o atual Decreto nº 9.057/2017 (BRASIL, 2017, p. 4), que regulamenta a LDB, no seu art. $1^{\circ}$, considera-se Educação a Distância:

\begin{abstract}
A modalidade educacional na qual a mediação didático-pedagógica nos processos de ensino e aprendizagem ocorra com a utilização de meios e tecnologias de informação e comunicação, com pessoal qualificado, com políticas de acesso, com acompanhamento e avaliação compatível, entre outros, e desenvolva atividades educativas por estudantes e profissionais da educação que estejam em lugares e tempos diversos (BRASIL, 2017, p. 4).
\end{abstract}

Com isso, e de acordo com Santos (2017), a EAD pode se tornar uma importante política pública social e que cabe ao poder público zelar por sua qualidade e oferta, Moraes (2010) firma que a oferta de cursos na modalidade a distância contribui para a universalização da educação no país e contribui para alcançar as metas do Plano Nacional de Educação (PNE) atualmente em vigor e, garantir aos estudantes melhores perspectivas de qualificação profissional.

Com a Reforma do Ensino Médio (Lei n. ${ }^{\circ}$ 13415/17) o Ministério da Educação (MEC), em 2018, autorizou a oferta parcial de cursos de ensino médio à distância: até 30\% da grade/carga horária dos cursos poderá ser realizada na modalidade EAD, respeitando-se contextos; realidades locais e decisões dos conselhos de educação de cada unidade federativa (BRASIL, 2017).

Uma das preocupações na oferta do ensino médio EAD na Bahia são os índices de qualidade de ensino, o Índice de Desenvolvimento da Educação Básica (IDEB), por exemplo, é realizado periodicamente pelo MEC, mas há alguns anos o estado não tem alcançado as metas estipuladas para a melhora de sua qualidade estão abaixo do esperado (BAHIA, 2018).

No contexto baiano, a região do semiárido sofre diretamente com fatores que contribuem para esses baixos índices como: abandono escolar; grande extensão territorial da Bahia; baixa qualidade do transporte escolar ou sua falta; população rural; difícil acesso às 
comunidades rurais (em especial na época das chuvas); luta pela sobrevivência, falta de emprego e migrações sazonais para outras regiões do País, com isso, é necessária uma política de flexibilização das aulas e a ampliação de sua oferta em todo o território baiano (BAHIA, 2018).

\section{Políticas Públicas em Educação à Distância}

A universalização da educação básica, em especial o ensino médio, aos brasileiros jovens e adultos é uma das metas do PNE entre o período de 2014 a 2024. A EAD pode contribuir de forma significativa como alternativa democrática e eficiente ao acesso ao Ensino Médio e sua oferta e qualidade devem seguir as mesmas diretrizes da educação adotadas pela LDB e Base Nacional Comum Curricular (BNCC) já em fase de implantação no país.

Segundo Ropoli (2002) de todas as fases na história da EAD no Brasil, a última geração tem vivenciado uma comunicação instantânea e de alta velocidade que contribui para um crescimento da procura por essa modalidade de forma significativa, Santos (2017) afirma que esse crescimento significativo elimina barreiras antes intransponíveis e democratiza o acesso à educação de qualidade em todos os níveis desde o ensino médio, graduação até a pós-graduação, por exemplo.

Em 2018, a Coordenação de Aperfeiçoamento de pessoal de Nível Superior (CAPES) através da Portaria n. ${ }^{\circ}$ 275/18 autorizou, às Instituições de Ensino Superior (IES), a criação de cursos de mestrado e doutorado na modalidade à distância, com isso o Brasil iguala a outros países que regulamentam a pós-graduação EAD como Portugal, Austrália, Espanha e Reino Unido (BRASIL, 2018).

A grande preocupação futura deverá ser com a qualidade dos cursos ofertados como apontam Levy (1999), Belloni (2003), Moran (2009) e Cassundé (2017). Para eles as instituições que irão ofertar esses cursos devem se preocupar com capacitação profissional de seus professores, construção de metodologias inclusivas e adaptadas à realidade de seus alunos.

Há uma quebra de cultura e com isso, uma boa transição entre as modalidades presencial e EAD é importante. Um bom exemplo disso é que no início de 2019, segundo Pinho (2019) 
alguns Conselhos Profissionais proibiram egressos de cursos EAD obterem registro nos

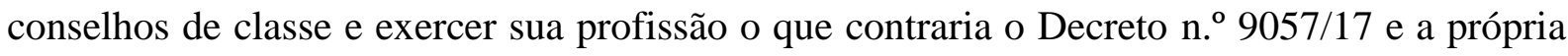
LDB, que regulamenta a educação à distância e, estabelece que as atividades presenciais previstas nos projetos pedagógicos dos cursos EAD devem ser realizadas em locais adequados em acordo com as Diretrizes Curriculares Nacionais, o que garantiria equivalência aos cursos em ambas as modalidades (BRASIL, 2017).

Assim, em qualquer uma das modalidades o uso das TICs é bastante valorizado na EAD (CASSUNDÉ, 2016). O Brasil tem promovido acesso a uma formação técnica de nível superior como a criação da Universidade Aberta do Brasil (UAB) e média através da Escola Técnica Aberta do Brasil (e-Tec Brasil). Ambas ofertadas em conjunto com universidades e institutos públicos reconhecidos pelo MEC, presente em todas as unidades federativas. Com isso, buscase a qualificação e oferta de educação de qualidade a cidadãos que vivem em localidades sem cursos presenciais e de difícil acesso (SANTOS, 2017).

\section{O Ensino Médio com Intermediação Tecnológica (EMITEC)}

Segundo dados do IBGE até o ano de 2017 a Bahia detinha a maior população rural do Nordeste, cerca de 3,7 milhões de habitantes. Garantir o acesso ao ensino médio a toda essa população é um dos grandes desafios logísticos e financeiros para a superação das desigualdades sociais que a exclusão a essa etapa da educação básica podem provocar RABELO (2006).

Em 2011 através da Portaria Estadual n. ${ }^{\circ} 424 / 11$ o governo baiano criou o Programa Ensino Médio com Intermediação Tecnológica (EMITEC) tendo como perspectiva garantir acesso universal ao ensino médio à população baiana e considerando fatores como baixos índices de qualidade, evasão e reprovação (BAHIA, 2011).

O ensino médio EAD que visa suprir demandas de formação educacional aos 417 municípios do Estado, promover a superação de carência de professores qualificados e superação de desigualdades socioculturais e existentes tendo como objetivo formar cidadãos de forma contínua e integral para o exercício da cidadania (BAHIA, 2018). 
O EMITEC está alinhado com os objetivos da Política Nacional de Desenvolvimento Regional (PNDR) para atender estudantes que residem em localidades rurais de difícil acesso, comunidades quilombolas, tribos indígenas e população carcerária, por exemplo, (BAHIA, 2011).

Um grande desafio do EMITEC é preservar a cultura local, valorizar os recursos naturais e especificidades econômicas, sociais e ambientais onde é inserido. Uma das metas na implantação do programa segundo Bahia (2011) é promover acesso à educação pública de qualidade em todo o território da Bahia, reduzir desigualdades e aumentar o Índice de Desenvolvimento Humano (IDH) das comunidades assistidas.

Quanto às potencialidades no uso das TIC, Rabelo (2006, p. 75) a sua utilização “[...] não só o atendimento a grandes contingentes de alunos, dispersos geograficamente, mas também a igualdade de oportunidades educativas e, consequentemente, a inclusão social". Com isso, o uso de equipamentos tecnológicos podem se tornar grandes aliados na superação das desiguales educacionais, reduzir a marginalidade, a pobreza e contribuir de forma positiva na formação de cidadãos em situação de vulnerabilidade social.

O EMITEC se utiliza do software Internet Protocol Television (IPTV) em suas tele aulas ele garante maior interatividade entre professores e alunos. As aulas virtuais são presenciais e transmitidas via satélite, em tempo real, a todos os polos na Bahia a partir do Instituto Anísio Teixeira (IAT) em Salvador e mediadas por professores especialistas e acompanhadas por monitores em cada polo do estado (BAHIA, 2011).

Além das tele aulas, outro recurso importante é o uso de um Ambiente Virtual de Aprendizagem (AVA), no caso do EMITEC utiliza-se do Modular Object-Oriented Dynamic Learning Environment (Moodle) um software livre, customizado, onde são inseridas informações administrativas e de apoio pedagógico: como legislações; vídeos; áudios; textos; livros e periódicos, que pode ser acessado remotamente tanto no polo quanto nas casas dos estudantes pelo computador ou celular (BAHIA, 2011).

Com relação à metodologia do EMITEC, os alunos têm maior autonomia na construção da sua aprendizagem, interagem com outros colegas de outras partes do Estado, são levados a propor soluções criativas e buscar suas respostas de forma mais investigativa. Com isso, a sua aprendizagem se torna mais significativa. Para Ausubel $(1978$, p. 159) uma aprendizagem 
significativa é aquela que "[...] acontece quando uma informação nova é adquirida mediante um esforço deliberado por parte do aprendiz em ligar a informação nova com conceitos ou proposições relevantes preexistentes em sua estrutura cognitiva [...]”.

Trabalhar com essa metodologia, a princípio é bastante desafiador aos professores do programa, com isso promover a sua formação continuada é fundamental. Para Cassundé (2016), Cassol (2001), Coronato (2009) e Saldanha (2013), o domínio no uso dos diversos recursos tecnológicos é essencial aos professores para que haja uma interação metre-discente satisfatória e personalizada.

O curso do EMITEC é classificado como um curso de Ensino Médio regular presencial com intermediação tecnológica porque possui a mesma carga horária de 3000 horas/aulas das demais modalidades presenciais, os tempos de aprendizagem são estruturados em três tempos, com aulas presenciais diárias toda a semana, de segunda a sexta-feira, organizados em tempos de aula, com três momentos específicos: exposição, produção e interatividade (BAHIA, 2011).

\section{Materiais e Métodos}

O presente trabalho apresenta-se como uma pesquisa exploratória fundamentada na abordagem qualitativa baseando-se nas definições de Collis (2005), Hair Jr. (2005) Yin (2005). Para Gonsalves (2007, p. 67) a pesquisa exploratória é aquela que "se caracteriza pelo desenvolvimento e esclarecimento de ideias, com objetivo de oferecer uma visão panorâmica, uma primeira aproximação a um determinado fenômeno que é pouco explorado".

Gil (1999, p. 43) explica que a pesquisa exploratória envolve os participantes da pesquisa de modo que estes possam contribuir para a compreensão do objeto a ser pesquisado:

Um trabalho é de natureza exploratória quando envolver levantamento bibliográfico, entrevistas com pessoas que tiveram (ou têm) experiências práticas com o problema pesquisado e análise de exemplos que estimulem a compreensão. Possui ainda a finalidade básica de desenvolver, esclarecer e modificar conceitos e ideias para a formulação de abordagens posteriores.

Para Bogdan e Biklen (1994, p. 149) a maioria das pesquisas qualitativas faz uso de muitos recursos para desenvolvê-la, concorda-se com elas quando afirmam que "embora 
discutamos diferentes tipos de dados separadamente, é importante salientar que eles raramente se encontram isolados na pesquisa". Assim, na abordagem qualitativa tem-se como propósito compreender de forma ampla como os sujeitos da pesquisa se comportam in loco, é necessário que o pesquisador ganhe a confiança do sujeito e desta forma, espera-se que os dados coletados sejam um reflexo de sua realidade investigada.

Para isso, foi utilizado um questionário como procedimento de coleta de dados. Segundo Gil (1999, p.128) questionário pode ser definido "como a técnica de investigação composta por um número mais ou menos elevado de questões apresentadas por escrito às pessoas, tendo por objetivo o conhecimento de opiniões, crenças, sentimentos, interesses, expectativas, situações vivenciadas etc.”.

Considerando o contexto do semiárido baiano e suas dificuldades enfrentadas o local escolhido para a realização desse trabalho foi uma escola pública municipal localizada na comunidade de Bananeiras, distrito rural da cidade de Pindobaçu, distante $404 \mathrm{~km}$ de Salvador pela BR 407, considerada remanescente quilombola e de difícil acesso, região de atuação do Centro Regional de Ensino Médio com Intermediação Tecnológica (CEMIT) localizado no 25. ${ }^{\circ}$ Núcleo Territorial de Senhor do Bonfim (NTE-25) vinculado à Secretaria Estadual de Educação da Bahia (SEC) (BAHIA, 2018).

Esse núcleo de educação é responsável por coordenar unidades do EMITEC nas cidades de Andorinha, Antônio Gonçalves, Caldeirão Grande, Campo Formoso, Filadélfia, Jaguarari, Senhor do Bonfim, Pindobaçu e Ponto Novo (BAHIA, 2018).

O presente trabalho foi elaborado tendo como base o ponto de vista de três professores mediadores que atuam no EMITEC na comunidade de Bananeiras no Colégio Municipal Telésforo Silveira de Menezes no turno noturno. Seguindo um roteiro definido em etapas: $\mathrm{Na}$ primeira etapa foram realizados estudos e levantamento documental e pesquisa bibliográfica, com o intuito de fundamentar esse trabalho e sistematizar discussões sobre as políticas públicas em educação à distância no ensino médio.

Na segunda etapa correu o contato com o local da pesquisa e elaboração do questionário a ser aplicado e termo de participação na pesquisa seguindo os termos de Marconi e Lakatos (1999). Na terceira etapa foi aplicado o questionário estruturado aos professores-monitores que trabalham com o EMITEC no Colégio Municipal Telesforo Silveira de Menezes no distrito de 
Bananeiras, município de Pindobaçu, na Bahia. Entre 11 e 14 de março de 2019. Em seguida houve a tabulação dos dados e a escrita final da pesquisa.

Os dados do questionário foram tabulados em duas partes: na primeira coleta de dados pessoais sobre os participantes: gênero, idade, estado civil, número de filhos, formação, experiência profissional e tipo de vínculo trabalhista com o EMITEC.

O objetivo dessas questões foi descobrir qual a qualificação desses profissionais para trabalhar com o EMITEC, tomando como referência o Projeto Político Pedagógico do Programa e seus acordos com a prefeitura local.

A segunda parte do questionário, semiestrutura, oito questões no total, questionou aos participantes aspectos gerais sobre o desempenho de suas funções, ambiente de trabalho e quais os impactos do programa para a comunidade. O objetivo foi perceber na visão do participante quais os impactos do EMITEC para a comunidade e a importância do trabalho deles nesse contexto.

\section{Resultados e discussões}

Algumas características do Projeto Político pedagógico (PPP) do Ensino Médio com Intermediação Tecnológica ressaltam a importância do professor mediador tais como mediar e intervir junto aos estudantes na sua aprendizagem, ter uma formação adequada, residir próximo ou na própria comunidade em que o EMITEC esteja instalado, possua aptidão para trabalhar com ferramentas tecnológicas em educação, tenha uma noção geral sobre os conteúdos do ensino médio e sobre a realidade local de sua comunidade além de ter disponibilidade para capacitação e formação, quando disponível pelos núcleos regionais do Programa.

Dos participantes pode-se constatar que são profissionais com ensino superior completo ou em curso. Um deles com curso de especialização concluído.

Tais aspectos confirmam a qualidade profissional mínima exigida pelo Estado para atuação da função de mediador do Programa, todos têm domínio sobre ferramentas digitais de aprendizagem e se utilizam de redes sociais para compartilhar informação e troca de material com os seus alunos. 
Com relação ao vínculo empregatício, apenas um mediador é funcionário efetivo do município de Pindobaçu tendo uma carga horária de 60 h dispensada às suas funções conjuntas de professor no município e mediador do EMITEC. Os outros dois mediadores são servidores do Estado Bahia contratados sob Regime Especial de Direito Administrativo (REDA),

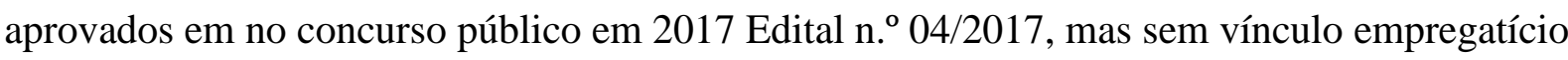
com o Estado da Bahia.

Algo que chama a atenção nesse edital é que se exige apenas o Ensino Médio para a função de professor mediador. O que contraria Projeto Político Pedagógico do EMITEC uma vez que esse exige formação em nível superior, preferencialmente licenciatura, para a função de mediador.

Considerando, contextos e realidades gerais uma das hipóteses desse descumprimento do PPP pode ser a pouca existência de profissionais com essa formação nas comunidades em que o programa se insere.

Apesar da pouca exigência por parte do Estado para a sua contratação, todos os professores atuam ou já atuaram na comunidade como professores dos alunos que monitoram no EMITEC, o que é verificado com o respeito que eles mantêm com os alunos, domínio de classe e compromisso com a aprendizagem dos mesmos.

Quanto ao questionário foi perguntada qual a importância do trabalho do mediador dentro do EMITEC. O objeto desse quesito foi verificar se cada um dos participantes tem noção sobre a importância do seu papel profissional. Há uma harmonia bem interessante na fala dos profissionais:

O meu papel é contribuir com a aprendizagem dos meus alunos. O que eu sei passo para eles da melhor forma possível. Escuto eles e eles me solicitam para esclarecer exercícios ou discutir um pouco sobre os temas das aulas. (Mediador 1).

Eu ajudo os alunos a intermediar as aulas, organizar a turma, fazer frequência e principalmente ouvir os alunos e suas necessidades. (Mediador 2).

O nosso papel não é substituir o professor especialista, mas colaborar para a aprendizagem dos alunos como um todo. Eu tento estimular eles a não desistir, fazer atividade e acompanhar as aulas mesmo em casa e fazer os exercícios e trabalhos, incluindo educação física. (Mediador 3). 
Observando as suas respostas, fica claro que eles conseguem compreender qual o papel da função do mediador do EMITEC e principalmente o quanto é importante o diálogo e o estímulo deles para que os alunos pratiquem os exercícios e não faltem aos encontros na escola. As respostas dos mediadores estão em acordo com o que é previsto no Projeto do EMITEC e nas falas de Cassundé (2016) que nos diz que a formação docente e sua capacitação para o bom desempenho com tecnologias digitais e a EAD são fundamentais.

Foi questionada aos mediadores qual a função deles na Escola em que atua o EMITEC e com os alunos. Um dos mediadores respondeu que:

A minha função na escola é chegar mais cedo, ligar o computador e a TV, organizar a sala e esperar os alunos, depois fazer a frequência, anotar os temas das aulas e orientar os alunos a pesquisar na biblioteca do colégio, sentar e fazer trabalhos em grupos com ou sem minha ajuda (Mediador 1).

Os outros mediadores demonstraram um pouco mais de sensibilidade sobre a presença dos alunos e o desenvolvimento:

Eu organizo a sala e faço a frequência, busco saber quem faltou, ligo para os alunos atrasados que já começou a aula, faço anotações e contribuo com a harmonia da sala, não deixo os alunos bagunçar e puno os que não querem assistir as aulas. (Mediador 2)

Eu me preocupo com a organização da sala, limpeza, se tem conexão e se os computares e TV estão funcionando. Ajudo os alunos a fazer seus exercícios e busco saber quando alguém falta o motivo. (Mediador 3).

Nesse contexto, o papel do mediador não é somente de ligar máquinas e imprimir atividades e aplicá-las aos alunos. Eles precisam se dispor a ajudar e contextualizar as situações com os alunos. Uma tarefa árdua e às vezes desgastante. É preciso observar que o EMITEC atua em parceria a gestão local das escolas parceiras, sendo às vezes necessário recorrer à direção da escola ajuda para controlar os alunos em sala de aula, como narra um dos professores:

.. Às vezes os alunos engrossam e para a gente não perder a cabeça pede ajuda da direção da escola que sempre é parceira. (Mediador 2).

O Colégio em que o EMITEC atua na comunidade e de Bananeiras tem uma sala de direção, uma sala de coordenação, 6 (seis) salas de aula, uma biblioteca, uma sala de professores e uma cantina, quadra poliesportiva descoberta e uma área com jardins e pátio livre.

Foi questionada aos mediadores qual a importância do EMITEC para a comunidade de Bananeiras. Dos três professores apenas um não reside na localidade o que aumenta o grau de 
confiança nas respostas dos monitores porque eles vivenciam e convivem com os alunos, que são seus ex-alunos, vizinhos ou conhecidos.

A garantia do acesso ao ensino médio de mães e pais de família que não tiveram oportunidade no passado e como a comunidade não tem escola presencial é importante. (Mediador 1).

Importante para as pessoas sem oportunidade, os alunos não tem condição de sair da comunidade e não tem transporte para o seu deslocamento para outras cidades à noite, que é a hora que eles têm mais disponibilidade. (Mediador 2).

Muitos da comunidade não sabem nem o que é o EMITEC, pensam que é uma escola normal, e sabem que depois da $8 .^{a}$ série, $9 .^{\circ}$ ano eles podem prosseguir nos seus estudos. (Mediador 3).

Foi questionado se o EMITEC contribui de alguma forma com a perspectiva de mudança e crescimento da comunidade. As respostas foram bem simples e positivas.

A primeira turma da comunidade se formou ano passado e os ex-alunos já estão se preparando para o ENEM agora em 2019. (Mediador 1).

Tem aluno que já passou em vestibular de faculdade privada e já pensa em ser engenheiro. A visão de futuro e possibilidade de sair da comunidade foi amplificada. (Mediador 2).

Sim. O EMITEC possibilita ao aluno aumentar e enriquecer os conhecimentos em geral, também a possibilidade de ingressar na faculdade. (Mediador 3).

Todos os monitores afirmaram que são respeitados e se sentem valorizados pelos alunos. Diante dessa constatação foi questionado aos monitores de que forma o trabalho deles impacta positivamente na vida dos alunos do programa:

Tem aluno que só não desistiu porque eu ajudei a estudar, tirar dúvidas e chamar no zap para vir assistir as aulas. (Mediador 1).

Eu contribuo no que posso ajudo eles nas tarefas nos exercícios e na ordem da turma. (Medidor 2).

Eu acredito que em tão pouco tempo os alunos conseguem superar as dificuldades em estudar sozinhos às vezes, eles precisam que eu incentive e estimular eles a estudar, entregar as tarefas nos prazos e não faltar e nem bagunçar. (Mediador 3).

Todos responderam que sobre o acesso ao ensino médio o EMITEC melhorou a vida dos jovens e adultos Segundo mediador 2: "Eram jovens sem perspectivas de mudança de vida. A transformação é processual e progressiva. Os frutos do programa começaram a ser colhidos no ano passado". Com isso, enquanto política pública em educação o EMITEC, aos poucos conseguirá transformar a vida dos moradores da comunidade. Para um dos mediadores: 
Nem todos os alunos vêm para a escola porque que querem aprender, mas os que vêm percebem que tem nas mãos a chance da vida. (Mediador 1).

A última questão investigou sobre as dificuldades enfrentadas pelos mediadores trabalhando com o EMITEC. Todos afirmaram que a conectividade é a principal queixa dos mediadores e alunos.

Às vezes ficamos sem aulas porque o sinal cai. E o Estado demora mandar alguém para fazer manutenção. (Mediador 1).

Ano passado, a TV quebrou e ficamos sem assistir as aulas direito, o sinal fraco e a baixa qualidade do áudio também incomoda os alunos. (Mediador 2).

O sinal é fraco e os alunos quando precisam mandar questões pelo chat ao vivo não recebem a resposta do professore especialista a tempo, o que se certa forma é muito ruim. Eles se sentem excluídos nesse sentido. (Mediador 3).

É, pois, notório que a escola tem um papel muito importante na acomodação no EMITEC, às dificuldades enfrentadas pelos mediadores são exclusivamente de responsabilidade do Estado, uma vez que a baixa conectividade e o tempo de resposta lento não contribuem para uma aprendizagem de qualidade e universal, o que é preconizado pelo Projeto político do programa. Cabe ao Estado zelar pela qualidade da transmissão e manutenção dos sistemas, uma vez que as aulas são diárias e seguem uma rotina que não pode ser rompida sem reposições futuras.

\section{Considerações Finais}

Este trabalho apresenta uma pesquisa sob o Ensino Médio com Intermediação Tecnológica (EMITEC), em uma comunidade rural da cidade de Pindobaçu, sertão baiano, apresenta as contribuições do programa para o desenvolvimento da comunidade e a perspectiva de crescimento da mesma.

Foi apresentada uma visão interdisciplinar sobre o EMITEC, seus aspectos legais e locais de inserção. O interesse desse trabalho, realizado para a conclusão da Especialização em Gestão Pública Municipal foi de olhar o programa como uma política pública em educação e verificar quais os seus benefícios para a comunidade escolhida.

703 Id on Line Rev. Mult. Psic. V.13, N. 45, p. 691-706, 2019 - ISSN 1981-1179 Edição eletrônica em http://idonline.emnuvens-.com.br/id 
A questão de pesquisa foi respondida ao longo do texto. Para obter os dados e informações relevantes sobre a temática foi realizado um levantamento bibliográfico sobre a temática, fez-se uma abordagem sobre o contexto e justificativa de sua existência além de compreender o programa a partir da visão do mediador, profissional responsável por ser uma ponte entre os alunos e os professores especialistas.

No tocante à formação dos alunos e assistência dos alunos, os mediadores cumprem adequadamente o seu papel, mesmo não tendo sido exigido por parte do Estado essa formação em licenciatura para atuarem como mediadores.

Aponta-se que o EMITEC precisa melhorar alguns aspectos como conectividade e acessibilidade de tecnologias aos alunos. Enquanto política pública cumpre o seu papel de garantir acesso ao Ensino Médio às comunidades rurais e contribui com a mudança de perspectiva dos moradores e amplia as suas possibilidades de crescimento pessoal e profissional.

Com relação ao objeto desse trabalho, espera-se que ele possa ser ampliado em produções futuras sobre as políticas públicas em educação à distância, em especial após descobrir que a sua implantação em localidades rurais contribui para a mudança de vida das pessoas, melhora a perspectiva de vida e formação de jovens e adultos.

\section{Referências}

AUSUBEL, David Paul; NOVAK, Joseph Donald; HANESIAN, Helen. Psicologia educacional. Rio de Janeiro: Editora Interamerica, 1978.

BAHIA, Ensino Médio com Intermediação Tecnológica (EMITEC). Salvador: SEC, 2018.

Portaria n..$^{\circ}$ 424, 21 de jan. de 2011. Implanta o Programa Ensino Médio com Intermediação Tecnológica (EMITEC). Salvador: EGBA, 2011.

Projeto Base do Ensino Médio com Intermediação Tecnológica do Estado da

Bahia - EMITEC. Salvador: Secretaria de Educação, 2011.

IP. TV - Estúdio 1, 2 e 3, Salvador: Secretaria de Educação do Estado da Bahia, 2011. BOGDAN, R.; BIKLEN, S. Investigação qualitativa. Porto: Porto Editora, 1994. 
BELLONI, Maria Luiza. Educação a Distância. Campinas: Autores Associados, 2003.

BRASIL. Presidência da República. Casa Civil. Lei de Diretrizes e Bases da Educação Nacional. Brasília: Senado Federal, 2017.

Lei $\mathbf{n}^{\mathbf{0}} \mathbf{1 3 . 4 1 5 / 1 7}$, de 16 de fevereiro de 2017. Institui a política de fomento à implementação de escolas de ensino médio em tempo integral. Brasília, 2017.

Decreto $\mathbf{n}^{\mathbf{0}}$ 9057/17, de 25 de maio de 2017. Regulamenta o art. 80 da Lei ${ }^{\circ}$ 9394/96, que estabelece as diretrizes da educação nacional. Brasília, 2017.

Lei $\mathbf{n}^{\mathbf{0}}$ 9.394/96, de 20 de dezembro de 1996. Estabelece as diretrizes e bases da educação nacional. Brasília, 1996.

BRASIL. Coordenação de Aperfeiçoamento de Pessoal de Nível Superior. Portaria $\mathbf{n}^{\mathbf{0}}$ 275/2018. Autoriza Instituições de Ensino Superior criação de cursos de Mestrado e Doutorado na modalidade à distância. Brasília, 2018.

CASSOL, Rita Salete. Ensino médio à distância mediado pela internet - uma alternativa para alunos do Colégio Estadual Eleodoro Ébano Pereira. Dissertação de Mestrado (Mestrado em Engenharia de Produção). Universidade Federal de Santa Catarina, Florianópolis, 2001.

CASSUNDÉ, F. R. et al. A escola no país das maravilhas tecnológicas... Revista Tecnologias na Educação v. 8. 2016.

CASSUNDÉ, F. R. et al. A influência das condições institucionais... para o ensino na EAD: proposição de um modelo analítico. vol. 22. n.2. Sorocaba: Avaliação, 2017.

COLLIS, Jill; HUSSEY, Roger. Pesquisa em Administração: um guia prático para alunos de graduação e pós-graduação. Porto Alegre: Bookmann, 2005.

CORONATO, Miguel López. Nuevas tecnologias y su uso em educación. In SOTO, Ucy et al. (Orgs.) Linguagem, educação e virtualidade. São Paulo: Cultura Acadêmica, 2009.

GIL, A.C. Métodos e técnicas de pesquisa social. São Paulo: Atlas, 1999.

GONSALVES, Elisa Pereira. Conversas sobre a iniciação a pesquisa científica. Campinas: Editora Alínea, 2007.

HAIR JR., J.F.; BABIN, B.; MONEY, A.H.; SAMOUEL, P. Fundamentos de métodos de pesquisa em administração. Tradução Lene Belon Ribeiro. Porto Alegre: Bookman, 2005. 
IBGE - Instituto Brasileiro de Geografia e Estatística. Censo demográfico de 2010. Rio de Janeiro: IBGE, 2010.

LÉVY, P. A inteligência colectiva: para uma antropologia do ciberespaço. Lisboa: Ed. Instituto Piaget, 1994.

Cibercultura. Tradução de Carlos Irineu da Costa. Rio de Janeiro: Ed. 34, 1999.

MARCONI, Maria de Andrade; LAKATOS, Eva Maria. Técnicas de pesquisa. 3. Ed. São Paulo: Atlas, 1999.

MORAN, José Manuel. Aperfeiçoando os modelos de EAD existentes na formação de professores. Educação, Porto Alegre, v. 32, n. 3, p. 286-290, set./dez. 2009.

PINHO, A. Conselhos profissionais vetam alunos formados por educação a distância. Folha de S. Paulo, São Paulo, 12 abr. 2019. Disponível em:

<https://www1.folha.uol.com.br/educacao/2019/04/conselhos-profissionais-vetam-alunosformados-por-educacao-a-distancia.shtml>. Acesso em: 12 abr. 2019.

RABELO, Patrícia Fraga Rocha. Panorama atual da educação superior a distância no Brasil. In: ROCHA, Nívea Maria Fraga (Org.). Educação, desenvolvimento humano e responsabilidade social: fazendo recortes na multidisciplinaridade. Salvador: Os autores, 2006.

SALDANHA, Luís Cláudio Dallier. A teleaula em questão. Tear: Revista de Educação Ciência e Tecnologia, Canoas, v.2, n.2, 2013.

SANTOS, Letícia Machados dos; ARAÚJO, Helisângela Bordes de. Ensino médio com intermediação tecnológica (EMITEC): inclusão e escolarização na zona rural e regiões remotas. Salvador: SEC, 2017.

YIN, Roberto K. Estudo de Caso: planejamento e métodos. Porto Alegre: Bookmann, 2005.

\section{Como citar este artigo (Formato ABNT):}

PEREIRA, Eloi da Silva; SOUZA, Sirius Oliveira. Desenvolvimento de Políticas Públicas em Educação a Distância no Semiárido: O caso da implantação do EMITEC no Sertão Baiano. Id on Line Rev.Mult. Psic., 2019, vol.13, n.45, p. 691-706. ISSN: 1981-1179.

Recebido: 01/05/2019

Aceito 06/05/2019 